\title{
Laboreal
}

Volume $10 \mathrm{~N}^{\circ} 2$ | 2014

Análise ergonómica do trabalho e formação - Parte II

\section{A análise do trabalho : longevidade e desenvolvimento de um conceito}

El análisis del trabajo: longevidad y desarrollo de un concepto

L'analyse du travail : longévité et développement d'un concept

Work analysis: longevity and development of a concept

\section{Anne Lancry-Hoestlandt}

Tradutor. João Viana Jorge

\section{(2) OpenEdition}

\section{Journals}

\section{Edição electrónica}

URL: http://journals.openedition.org/laboreal/5017

DOI: 10.4000/laboreal.5017

ISSN: 1646-5237

\section{Editora}

Universidade do Porto

\section{Refêrencia eletrónica}

Anne Lancry-Hoestlandt, "A análise do trabalho : Iongevidade e desenvolvimento de um conceito », Laboreal [Online], Volume $10 \mathrm{~N}^{0} 2$ | 2014, posto online no dia 01 julho 2014, consultado o 24 setembro 2020. URL : http://journals.openedition.org/laboreal/5017 ; DOI : https://doi.org/10.4000/laboreal. 5017

Este documento foi criado de forma automática no dia 24 setembro 2020.

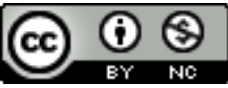

Laboreal está licenciado com uma Licença Creative Commons - Atribuição-NãoComercial 4.0 Internacional. 


\title{
A análise do trabalho : longevidade e desenvolvimento de um conceito
}

\author{
El análisis del trabajo : longevidad y desarrollo de un concepto \\ L'analyse du travail : longévité et développement d'un concept \\ Work analysis: longevity and development of a concept
}

\section{Anne Lancry-Hoestlandt}

Tradução : João Viana Jorge

\section{REFERÊNCIA}

Karnas, G., \& Salengros, P (1986). L'analyse du travail trente ans après Ombredane et Faverge. In R. Patesson. L'Homme et l'écran. Aspects de l'ergonomie en informatique (p. 331-340). Colloque "L'ergonomie en informatique", 1985, Nivelles. Bruxelles: Ed.de l'Université de Bruxelles.

\section{NOTA DO EDITOR}

http://dx.doi.org/10.15667/laborealx0214acpt

Este texto de Guy Karnas e Pierre Salengros [1] é uma das comunicações proferidas no decurso do Colóquio intitulado "A ergonomia em informática" organizado em Nivelles na Bélgica, em Novembro de 1985 por René Patesson e pelo Grupo de pesquisas em informática e ciências humanas da Université Libre de Bruxelles (1986). Investigadores do laboratório dirigido por Jean-Marie Faverge - laboratório que tinha estado implicado nas primeiras pesquisas europeias promovidas pela Comunidade Europeia do Carvão e do Aço (CECA) - Karnas e Salengros desenvolveram a prática da análise do trabalho numa grande variedade de postos e de situações de trabalho, enquanto método e enquanto objeto. Eles definem neste artigo "que ela (a análise do trabalho) não pode portanto conceber-se senão por referência a um objetivo em relação ao qual é 
'método"' (p. 332, tradução livre). Esta corrente de pesquisas e de práticas é oriunda dos trabalhos de Ombredane e Faverge nesse mundo dos anos 50 e 60 em que o trabalho era mais físico e em que as transmissões dos sinais informativos não eram muito simbolizadas. É particularmente interessante constatar e relembrar que esta corrente de pesquisas está vivamente presente nos anos $80 \mathrm{em}$ sectores de atividade diversos cujo desenvolvimento tecnológico, em rápida e constante expansão, veio perturbar e modificar radicalmente a quase totalidade das situações de trabalho.

2 O propósito dos autores é o de mostrar que trinta anos após a edição da obra de referência de Ombredane e Faverge (1955), os princípios fundadores da análise do trabalho eram suficientemente robustos e evolutivos para permitir a análise de situações de trabalho completamente novas e desconhecidas das dos anos 50. Agora, quase 60 anos após a publicação desta obra, esses conceitos são ainda ricos em novos desenvolvimentos adaptados às novas evoluções do trabalho. Foi o que pôs em evidência a jornada de estudo organizada pelo GRESHTO-CRTD no CNAM [ $\left.{ }^{2}\right]$ em 2012 consagrada ao livro de André Ombredane e Jean-Marie Faverge publicado em 1955 : “A análise do trabalho. Fator de economia humana e de produtividade" [3].

3 Faverge, retomado por Karnas e Salengros, constata que a ordem cronológica da aparição das análises do trabalho coincide com a evolução das modificações tecnológicas e ergonómicas do trabalho. Citemos o texto original: “- trabalhar é ocupar-se das posturas, realizar gestos ; - trabalhar é tratar a informação, é 'comunicar' com a matéria, seja diretamente ou com a ajuda de intermediários mais ou menos complexos, desde o painel, botão, pedal, até ao computador ou robô, passando pelo autómato; - trabalhar é também regular processos complexos originados, nomeadamente, a partir de interações entre as células de um sistema em que nós mesmos somos um dos elementos (isso é evidente) que é também um sistema; finalmente, trabalhar é recorrer a processos de pensamento que gerem as atividades anteriores ; assim, é implementar algoritmos, heurísticas, representações, estratégias. É esse o domínio que passou a ser a ergonomia cognitiva" (p. 332 e 333, tradução livre).

4 No quadro desse colóquio respeitante à Ergonomia Informática, os autores relevam três características salientes a ter em conta na análise do trabalho: “- a tomada de poder do homem sobre a sua atividade, os movimentos de humanização do trabalho e o desenvolvimento das técnicas informáticas no quadro de uma crise económica com as suas consequências na dinâmica organizacional da empresa" (p. 333 tradução livre). A previsão (pelo operador e não somente por um gabinete de métodos), a regulação da atividade, a possibilidade de intervir numa cadeia de disfuncionamentos (Faverge et al, 1966) são elementos decisivos para o interesse e as competências desenvolvidas no trabalho e portanto da tomada de poder do homem sobre a sua atividade; são aspetos importantes a pesquisar na análise do trabalho. Interligamos essas observações com os trabalhos mais recentes de Clot (2013) quando a propósito de uma reflexão de Malrieu lembra que "um trabalhador não pode viver duravelmente num ofício a menos que possa "fabricar" ofício para trabalhar (...) o ofício não é apenas uma atividade pessoal ou interpessoal. É também transpessoal e impessoal, história coletiva e "genérica" de um dado meio e normas sociais gerais e prescritas de uma profissão" (p. 148, tradução livre).

5 Se voltarmos ao texto de 1986, os autores assinalam num segundo ponto que conjuntamente com o desenvolvimento da análise do trabalho numa perspetiva estritamente ergonómica mais centrada no posto de trabalho in situ, correntes de 
pesquisa em psicologia social, sociologia, economia, interessaram-se pelos contextos de vida na qual o trabalhador evolui. Os autores fazem referência aos estudos respeitantes às ligações entre a vida no trabalho e a vida fora do trabalho abordando as questões das representações do trabalho para o homem e os sistemas de valores que lhe estão ligados. Evocando os conflitos temporais entre a vida no trabalho e fora dele assinalam as reinterpretações possíveis dos limiares de declarações de acidentes ou dos fatores influentes no absentismo, o que introduz a noção de "estilo", refletindo a conceção pessoal da vida no trabalho. Esta reversão do ângulo sob o qual a ergonomia aborda o trabalho (a pessoa fala para ela) leva inevitavelmente ao emprego de outros métodos na investigação e na análise, isto é, a entrevista e o questionamento.

6 Esta evolução permitiu aos ergónomos enriquecer as suas análises com pontos de vista psicossociais e trabalhar com psicólogos sociais e psicólogos do trabalho. Aludimos aqui nomeadamente no que respeita ao sistema de atividades vida no trabalho/vida fora do trabalho, aos trabalhos conduzidos por Curie (2000) e ao laboratório "Personalização e mudanças sociais" de Toulouse.

7 No terceiro e último ponto da sua apresentação aborda-se o desenvolvimento das técnicas informáticas num contexto de crise económica. Nos anos 80, fala-se de postos votados à codificação de dados acompanhados pelo sentimento de perda de autonomia e de liberdade ao pôr em prática os procedimentos ou mesmo do sentimento de despersonalização na relação com os clientes. Os primeiros estudos neste domínio dizem respeito à adaptação à máquina e começam a aparecer estudos sobre os aspetos psicossociológicos deste tipo de trabalho os quais vão em seguida associar aos seus questionamentos uma análise do trabalho. O que permitirá, nomeadamente, pôr em evidência, por exemplo, que a famosa "resistência à mudança" não é imputável a uma falta de motivação mas a uma perda da possibilidade de antecipar a tarefa, de dominar a sua atividade e, se for o caso, de recuperar de uma situação degradada.

8 Sem entrar em detalhe nestes estudos é também neste período que, com Leplat (1992) e Leplat e Hoc (1983) é introduzida a distinção entre análise da tarefa, descritiva e diagnóstica (prescrita, efetiva e real) e a análise da atividade nos seus aspetos observáveis e nos seus mecanismos subjacentes, inobserváveis e inferíveis. Numerosas técnicas ficam disponíveis para objetivar a tarefa e são frequentemente necessárias para pôr em prática a análise da atividade para a qual, além da observação eventualmente filmada, se encontram as entrevistas e questionários podendo associarlhes os métodos da psicologia clínica da atividade (auto-confrontação simples, cruzada e o método do sósia) (Clot, 2008).

9 O enriquecimento da análise do trabalho e da análise da atividade acompanha, por um lado, o desenvolvimento de novas formas de trabalho e por outro, importantes reflexões sobre sectores de atividades antigas cuja evolução e disfuncionamentos colocam numerosas interrogações. Em ergonomia novas temáticas se desenvolveram, as quais mostram que é possível transpor a análise do trabalho para situações em que se poderia pensar a priori que não diziam respeito ao seu campo de aplicação (domínios da ergonomia e da educação, da ergonomia e da multimédia, da saúde, da deficiência, dos transportes, dos serviços) (Lancry, 2009).

10 O desenvolvimento da análise do trabalho em meio escolar (Lancry-Hoestlandt, 2013, 2014) é exemplo de um possível reinvestimento. Tem como ponto de partida os conceitos de tarefa e de atividade, especificando-os e enriquecendo-os nomeadamente com as noções de prescrição explícita e implícita e de tarefa principal (a que é avaliada) 
e de tarefa secundária (pré requisito ou prévia à compreensão e à realização da tarefa principal). Este contributo permite também abordar a noção de fiabilidade retomando a conceção de Faverge, do homem enquanto agente de fiabilidade e de infiabilidade para ele próprio e para o sistema, daí a nossa retoma da definição de Leplat e de Terssac (1990) : "estudo dos fatores (das modalidades de implementação e de elaboração das competências) adequados à melhoria da qualidade do acoplamento homens X tarefas" (tradução livre). Em meio escolar trata-se de distinguir os fatores ou a combinação de fatores que favorecem, impedem ou complicam a realização da tarefa prescrita ou de tarefas secundárias. Fala-se de indicadores de fiabilidade quando o ator (ex : o aluno, o professor ou qualquer outro trabalhador) pode, pela sua ação própria acentuar ou provocar uma situação não fiável ou pelo contrário transportar elementos corretores que otimizam a situação e inibem os efeitos negativos geradores de erros e disfuncionamentos, quer dizer quando (ele) se torna agente de fiabilidade para si próprio ou para a estrutura. Estas primeiras abordagens têm de ser aprofundadas e completadas por uma análise conjunta da atividade do aluno e do professor.

11 Acresce portanto que é útil e precioso poder retomar e "voltar a dar a palavra" aos textos e pesquisas fundadoras das nossas disciplinas e constatar que as atualizações são possíveis e fecundas.

\section{BIBLIOGRAFIA}

Clot, Y. (2008). Travail et pouvoir d'agir. Paris : PUF.

Clot, Y. (2013). Philippe Malrieu et le travail : une personnalisation paralysée ? In A. BaubionBroye, R. Dupuy \& Y. Prêteur. (Eds). Penser la socialisation en psychologie. Actualité de l'œuvre de Philippe Malrieu (pp. 141-152). Toulouse : Erès.

Curie, J. (2000). Travail, Personnalisation, Changements sociaux. Archives pour les histoires de la psychologie du travail. Toulouse : Octarès.

Faverge, J-M., Olivier, M., Delahaut, J., Stephaneck, P., \& Falmagne, J.C. (1966).

L'ergonomie des processus industriels. Bruxelles : Editions de l'Institut de Sociologie de l'Université Libre de Bruxelles.

Lancry, A. (2009). L'ergonomie. Paris : PUF, Coll. Que sais-je?

Lancry-Hoestlandt, A. (2013). A propos d'ergonomie scolaire. In A. Drouin, (coord.). Ergonomie. Travail, Conception, Santé. Cinquantenaire de la Société d'Ergonomie de Langue Française - 1963-2013. (pp. 381-391).Toulouse : Octarès.

Lancry-Hoestlandt, A. (à paraître 2014). Le travail en herbe. L'analyse du travail en situation scolaire. In R. Ouvrier-Bonnaz \& A. Weill-Fassina (coord.). "L'analyse du travail" Ruptures et Evolutions. Toulouse : Octarès (édition électronique en accès libre).

Leplat, J. (coord). (1992). L'analyse du travail en psychologie ergonomique. Recueil de textes. Tome 1. Toulouse : Octarès. 
Leplat, J., \& Hoc, J. M. (1983). Tâche et activité dans l'analyse psychologique des situations. Cahiers de psychologie cognitive, 3, 1, 49-63.

Leplat, J. \& de Terssac, G. (1990). Les facteurs humains de la fiabilité dans les systèmes complexes. Toulouse : Octarès.

Ombredane, A. \& Faverge, J-M. (1955). L'analyse du travail. Paris : PUF.

Patesson, R. (coord) (1986). L'Homme et l'écran. Apports de l'ergonomie en informatique. Bruxelles : Editions de l'Université Libre de Bruxelles.

\section{NOTAS}

1. Karnas, G., \& Salengros, P (1986). L'analyse du travail trente ans après Ombredane et Faverge. In R. Patesson. L'Homme et l'écran. Aspects de l'ergonomie en informatique (p.331-340). Colloque “L'ergonomie en informatique", 1985, Nivelles. Bruxelles : Ed.de l'Université de Bruxelles.

2. Groupe de Recherche et d'Etude Sur l'Histoire du Travail et de l'Orientation du Centre de Recherche sur le Travail et le Développement du Conservatoire National des Arts et Métiers.

3. Esta Jornada deu origem a uma obra coordenada por R. Ouvrier-Bonnaz e A. Weill-Fassina, do GRESHTO-CRTD, CNAM (a sair em 2014) : "L'analyse du travail” Ruptures et Evolutions. Ed. Octarès. Toulouse (edição eletrónica de acesso livre).

\section{AUTORES}

\section{ANNE LANCRY-HOESTLANDT}

Conservatoire National des Arts et Métiers (CNAM)

Centre de Recherche sur le Travail et le Développement (CRTD)

Groupe de Recherche et d'Etude sur l'Histoire du Travail et de l'Orientation (GRESHTO), 41 Rue

Gay Lussac, 75005 Paris, France

anne.lancry@cnam.fr 